\title{
Contribution of Excitatory Chloride Conductance in the Determination of the Direction of Traveling Waves in an Olfactory Center
}

\author{
Satoshi Watanabe, Tsuyoshi Inoue, and Yutaka Kirino \\ Laboratory of Neurobiophysics, Graduate School of Pharmaceutical Sciences, The University of Tokyo, Bunkyo-ku, Tokyo 113-0033, Japan
}

Traveling waves have been found in the CNS of vertebrates and invertebrates. In the olfactory center [procerebrum (PC)] of the terrestrial slug Limax, periodic waves travel from the apex to the base with a frequency of $\sim 0.7 \mathrm{~Hz}$. The oscillation and propagation of waves have been thought to be mediated by the mutual connections of bursting neurons in the $\mathrm{PC}$. The direction of the wave is $\mathrm{Cl}^{-}$dependent, because lowering the $\mathrm{Cl}^{-}$concentration in the medium reverses the direction. The bursting neurons have a $\mathrm{Cl}^{-}$channel-coupled glutamate receptor (GluClR), and, using a calcium imaging technique, the receptor was found to be excitatory. Activation of the GluClR with its selective agonist ibotenate resulted in an increased frequency of the oscillatory neural activity recorded as a periodic local field potential. Depletion of cytoplasmic $\mathrm{Cl}^{-}$with $\mathrm{Cl}^{-}$-free saline abolished all of the ibotenate-induced effects. Perforated-patch-clamp recording in single $\mathrm{PC}$ neurons revealed a spatial difference in the $\mathrm{Cl}^{-}$-dependent periodic depolarizations in the bursting neurons, with a higher amplitude in the apical region. These results suggest the involvement of excitatory GluClRs in the unidirectional propagation of waves in the PC.

Key words: neural oscillation; wave propagation; olfaction; mollusk; procerebrum; glutamate; ibotenate; perforated patch recording; fluorescent $\mathrm{Ca}^{2+}$ indicator

\section{Introduction}

In many CNSs, there are oscillatory neural activities that are synchronized over a large area of the network (for review, see Ritz and Sejnowski, 1997). Often these network oscillations have phase lags within the network, resulting in traveling waves. Traveling waves arise as a result of the mutual interactions of oscillatory local circuits (Ermentrout and Kleinfeld, 2001) and have been found in olfactory centers (Kleinfeld et al., 1994; Lam et al., 2000), in the visual cortex in vivo (Prechtl et al., 1997), and in neocortical slices (Golomb and Amitai, 1997; Sanchez-Vives and McCormick, 2000). The phase difference along the network changes as it receives sensory inputs (Gervais et al., 1996). Such changes in the spatiotemporal pattern could modify the relationship between individual neurons constituting the network, making it possible to separate and integrate the neural activities encoding different sensory signals (Gelperin, 1999).

Analyses of mathematical network models with coupled oscillators have clarified the basic properties of oscillatory networks. For example, the local network with the highest intrinsic oscillatory frequency will have the earliest phase (Ermentrout and Kleinfeld, 2001). However, to fully understand the precise mechanisms underlying the traveling waves, both the membrane properties of single neurons and synapses should be characterized, but we have yet only partial knowledge about any of these parame-

\footnotetext{
Received Aug. 19, 2002; revised Dec. 18, 2002; accepted Jan. 14, 2003.

This work was supported by Grants-in-Aid 12048209, 12307053, 13210036, and 13771353 for Scientific Research from the Ministry of Education, Culture, Sports, Science, and Technology of Japan.

Correspondence should be addressed to Satoshi Watanabe, Laboratory of Neurobiophysics, Graduate School of Pharmaceutical Sciences, The University of Tokyo, 7-3-1 Hongo, Bunkyo-ku, Tokyo 113-0033, Japan. E-mail: satoshi@mayqueen.f.u-tokyo.ac.jp.

T. Inoue's present address: Department of Neurosciences, Case Western Reserve University, Cleveland, $\mathrm{OH} 44106$. Copyright $\odot 2003$ Society for Neuroscience $\quad$ 0270-6474/03/232932-07\$15.00/0
}

ters. Therefore, we analyzed the ionic basis of traveling waves in the olfactory center of the terrestrial mollusk Limax.

The olfactory center of the slug Limax shows regular oscillatory activity (Gelperin and Tank, 1990), and the oscillation has a phase lag along the procerebrum (PC), which is normally advanced in the apical region (Kleinfeld et al., 1994; Kawahara et al., 1997; Inoue et al., 1998). The direction of the wave propagation is therefore from the apex to the base. However, lowering the $\mathrm{Cl}^{-}$ concentration in the medium reverses the direction (Kleinfeld et al., 1994). Also, when the PC is locally lesioned, the locus of the lesion becomes the origin of wave propagation (Kleinfeld et al., 1994). These results suggest that the network architecture itself allows bidirectional wave propagation, and the direction depends on the difference in the excitability of the local networks, which depends on $\mathrm{Cl}^{-}$. The oscillatory activity of the $\mathrm{PC}$ is produced by a synchronized oscillation in the bursting PC neurons, which constitute $\sim 10 \%$ of the total PC neurons and are presumed to be local inhibitory interneurons (Kleinfeld et al., 1994; Watanabe et al., 1998). The activity level of the bursting neurons determines the oscillation frequency (Watanabe et al., 2001). The bursting neurons, but not the other type of PC neurons (nonbursting neurons), have a type of glutamate receptor coupled to a $\mathrm{Cl}^{-}$ channel (GluClR) that is activated by ibotenate (Watanabe et al., 1999). Moreover, as has been found in some mammalian neurons, $\mathrm{Cl}^{-}$conductances could have excitatory actions (Owens et al., 1996). Therefore, in the present work, we examined how $\mathrm{Cl}^{-}$mediated mechanisms are involved in the traveling waves.

\section{Materials and Methods}

Slugs Limax valentianus were hatched and cultured at our laboratory. For dissection, the slug $(0.5-1.0 \mathrm{gm})$ was anesthetized by injection of $\mathrm{Mg}^{2+}$ buffer solution that contained the following (in $\mathrm{mM}$ ): $60 \mathrm{MgCl}_{2}, 5$ glu- 
cose, and 5 HEPES, pH 7.6, into the body cavity. The circumesophageal ganglia were isolated and further dissected in a dish filled with $\mathrm{Mg}^{2+}$ buffer. The cerebral ganglion was isolated from the other ganglia, and the sheath covering the PC was removed with fine forceps. All recordings were made at room temperature $\left(20-24^{\circ} \mathrm{C}\right)$.

The saline solution used for the recordings contained the following (in mM): $70 \mathrm{NaCl}, 2 \mathrm{KCl}, 4.9 \mathrm{CaCl}_{2}, 4.7 \mathrm{MgCl}_{2}, 5$ glucose, and 5 HEPES, $\mathrm{pH}$ 7.6. Drugs were bath applied to the ganglion, which was placed in a chamber $(\sim 0.2 \mathrm{ml}$ in volume) that was continuously perfused. Because ibotenate is the only agonist known to activate the GluClR in Limax PC neurons (Watanabe et al., 1999), different batches of ibotenic acid from three suppliers (Sigma, St. Louis, MO; Research Biochemicals, Natick, MA; and Tocris Cookson, Bristol, UK) were used, and we confirmed that all of these gave similar results. Quisqualic acid was supplied by Sigma, and L-glutamic acid sodium salt was supplied by Nakalai Tesque (Kyoto, Japan). For the $\mathrm{Cl}^{-}$-free saline, $\mathrm{Cl}^{-}$was totally replaced by gluconate. For the $\mathrm{Na}^{+}$-free saline, $\mathrm{Na}^{+}$was replaced by tris[hydroxymethyl] aminomethane (Trizma base; Sigma).

The local field potential (LFP) of the PC was recorded from the posterior surface of the PC using a glass electrode filled with saline solution (Kawahara et al., 1997). The signal was differentially amplified and bandpass filtered at $0.5-30 \mathrm{~Hz}$. The signals were recorded on a DAT recorder (PC204Ax; Sony, Tokyo, Japan). The frequency of the LFP oscillation was evaluated using at least five cycles of oscillations just before and 10 sec after the onset of the perfusion with ibotenate. The frequency was calculated as the inverse of the averaged cycle period.

Calcium imaging in single $\mathrm{PC}$ neurons was done in a dissociated culture of PC neurons (Rhines et al., 1993). The PC was desheathed and isolated in $\mathrm{Mg}^{2+}$ buffer, digested with $1 \%$ protease (type IX; Sigma) at $34^{\circ} \mathrm{C}$ for $1 \mathrm{hr}$, and dissociated by trituration. Fifty microliters of cell suspension was placed on a poly-lysine-coated glass-bottomed dish (MatTek, Ashland, MA) at the final density of two PCs per dish, and, $2 \mathrm{hr}$ later, $2 \mathrm{ml}$ of saline solution was added to the dish, after which the cells were further cultured for $1-2 \mathrm{~d}$ at $20^{\circ} \mathrm{C}$. Cells were loaded for $12 \mathrm{~min}$ at $28^{\circ} \mathrm{C}$ with the AM of the $\mathrm{Ca}^{2+}$ indicator fura-2 (fura-2 AM; Dojindo, Kumamoto, Japan) dissolved in saline solution at the final concentration of $5 \mu \mathrm{M}$. The cells were then postincubated in saline solution for $20 \mathrm{~min}$ at $28^{\circ} \mathrm{C}$. Image acquisition was performed with an imaging system (MCID; Imaging Research, St. Catharines, Ontario, Canada) equipped with a CCD camera (CCD-72; Dage-MTI, Michigan City, IN) with an image intensifier head (C2400 - 68; Hamamatsu Photonics, Hamamatsu, Japan) set on an inverted microscope (IX 70; Olympus, Tokyo, Japan). A filter set (XF04; Omega Optics, Brattleboro, VT) (excitation filters, $340 \pm$ 7.5 and $380 \pm 7.5 \mathrm{~nm}$; dichroic mirror, $430 \mathrm{~nm}$; and emission filter, $510 \pm 20 \mathrm{~nm}$ ) was used for epifluorescent illumination, and the excitation filter was switched by a filter changer (Lambda-10; Sutter Instruments, Novato, CA). Image sets were acquired every 1 or 2 sec during the session of $120 \mathrm{sec}$, for the last $90 \mathrm{sec}$ of which the drug solution was perfused. The typical number of cells found in an image was between 100 and 1000 . To detect the cells showing a cytoplasmic $\mathrm{Ca}^{2+}$ concentration $\left(\left[\mathrm{Ca}^{2+}\right]_{\mathrm{i}}\right)$ rise, ratio $\left(F_{340} / F_{380}\right)$ images at 0 and $80 \mathrm{sec}$ were compared, and the cells showing an increase in the ratio value by $>0.2$ were counted as responding cells.

Calcium imaging in the intact $\mathrm{PC}$ was performed using the AM of the calcium indicator dye rhod-2 (rhod-2 AM; Dojindo) by the method described previously (Inoue et al., 1998). The cerebral ganglion was incubated with $50 \mu \mathrm{M}$ rhod- $2 \mathrm{AM}$ and $0.025 \%$ cremophor EL (a dispersing reagent; Sigma) for $40 \mathrm{~min}$ at $28^{\circ} \mathrm{C}$. Optical recording was performed using a MOS-based camera system (HR-Deltaron 1700, Fuji Photo Film, Tokyo, Japan) and an inverted microscope (IX-70; Olympus) equipped with a $10 \times($ numerical aperture, 0.40$)$ or $20 \times$ (numerical aperture, 0.75 ) objective lens and a $100 \mathrm{~W}$ halogen lamp with a stabilized DC power supply. A filer set (U-MNG; Olympus) with an excitation filter (530-550 $\mathrm{nm})$, a dichroic mirror $(570 \mathrm{~nm})$, and an emission filter $(>590 \mathrm{~nm})$ was used. The images were acquired at the rate of $76.8 \mathrm{msec} /$ frame. The original images $(128 \times 128$ pixels $)$ were converted off-line into ratio $(\Delta F / F)$ images by dividing each image by the time-averaged image, using a custom-made program for Matlab (MathWorks, Natick, MA). The peak response normalized by the prestimulus amplitude of $\mathrm{Ca}^{2+}$ oscil-
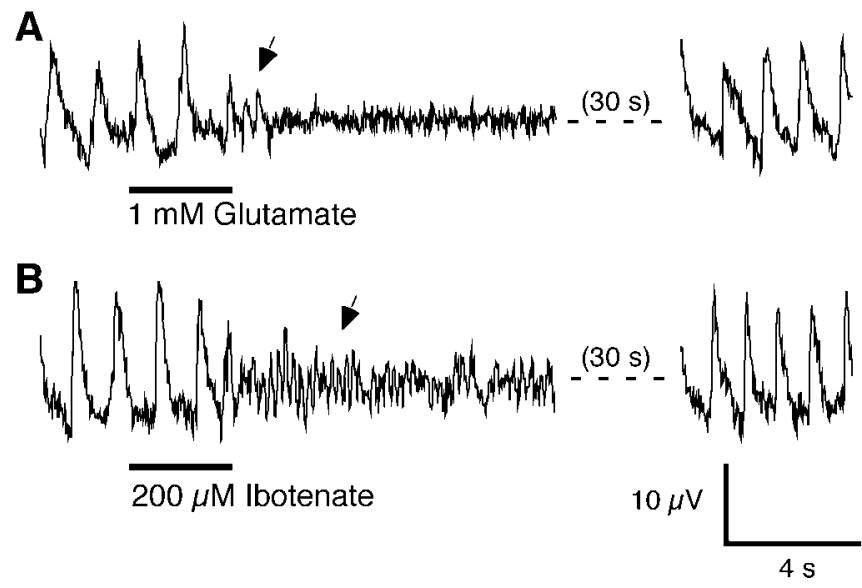

Figure 1. Effect of glutamate receptor agonists on the LFP oscillation of the PC. A, Perfusion with $1 \mathrm{~mm}$ glutamate (duration, 3 sec; indicated by the horizontal bar) slightly enhanced the LFP frequency (arrow), followed by a complete suppression. After the washout for $30 \mathrm{sec}$, the oscillation recovered. $B$, Perfusion with $200 \mu \mathrm{m}$ ibotenate (duration, $3 \mathrm{sec}$; indicated by the horizontal bar) strongly enhanced the frequency of the LFP oscillation (arrow). After the washout for 30 $\mathrm{sec}$, the oscillation recovered to the initial level.
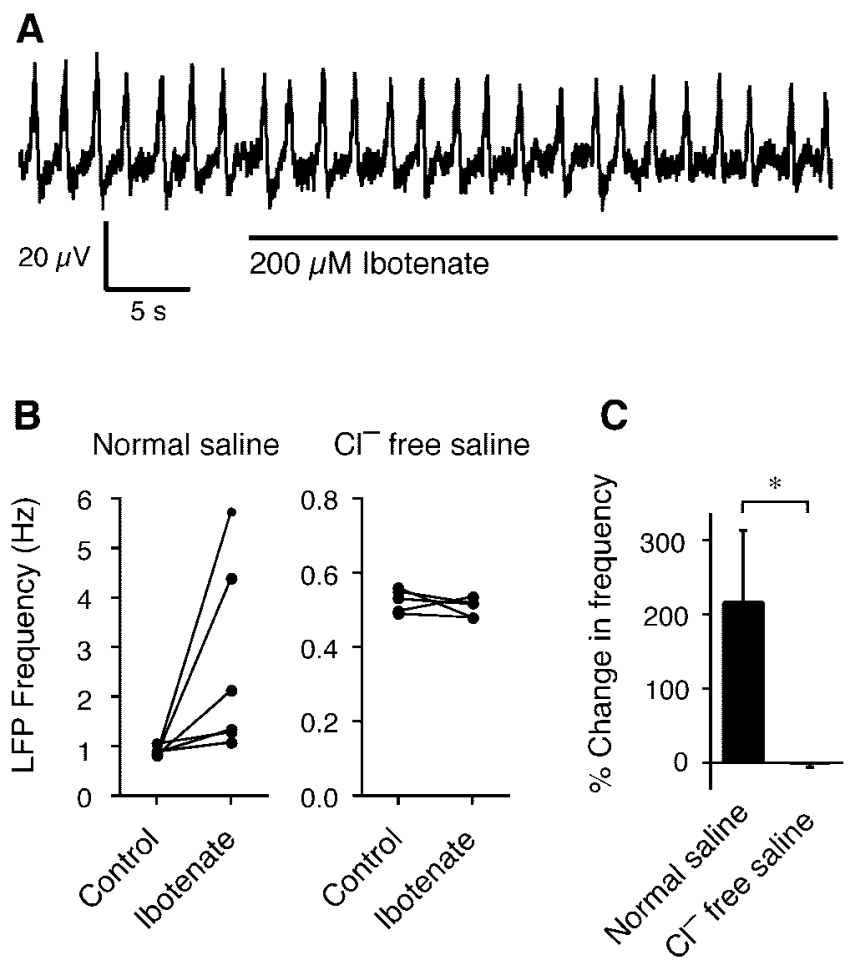

Figure 2. Effect of ibotenate on the LFP oscillation is $\mathrm{Cl}^{-}$dependent. $A$, Perfusion with ibotenate (indicated by the horizontal bar) in $\mathrm{Cl}^{-}$-free saline did not change the frequency of the LFP oscillation. $B$, Frequency changes caused by ibotenate in normal saline and in $\mathrm{Cl}^{-}$-free saline. Control and Ibotenate indicate the frequencies before and during the perfusion with ibotenate. For the $\mathrm{Cl}^{-}$-free condition, only those preparations that showed regular oscillations were included. C, Summary of the frequency changes with ibotenate in normal saline and in $\mathrm{Cl}^{-}$-free saline. The frequency changes under these two conditions were significantly different ( $t$ test; ${ }^{*} p<0.05$ ).

lation was calculated from the peak $\left(R_{\text {peak }}\right)$ and bottom $\left(R_{\text {bottom }}\right)$ ratio values before the onset of perfusion with ibotenate and the peak ratio value during the perfusion $\left(R_{\text {peak,IA }}\right)$ as $\left(R_{\text {peak,IA }}-R_{\text {bottom }}\right) /\left(R_{\text {peak }}-\right.$ $\left.R_{\text {bottom }}\right)$. The frequency of the calcium oscillation was calculated in the same way as the LFP oscillation.

Nystatin perforated-patch recording of the bursting PC neuron was made essentially by the method described previously (Watanabe et al., 


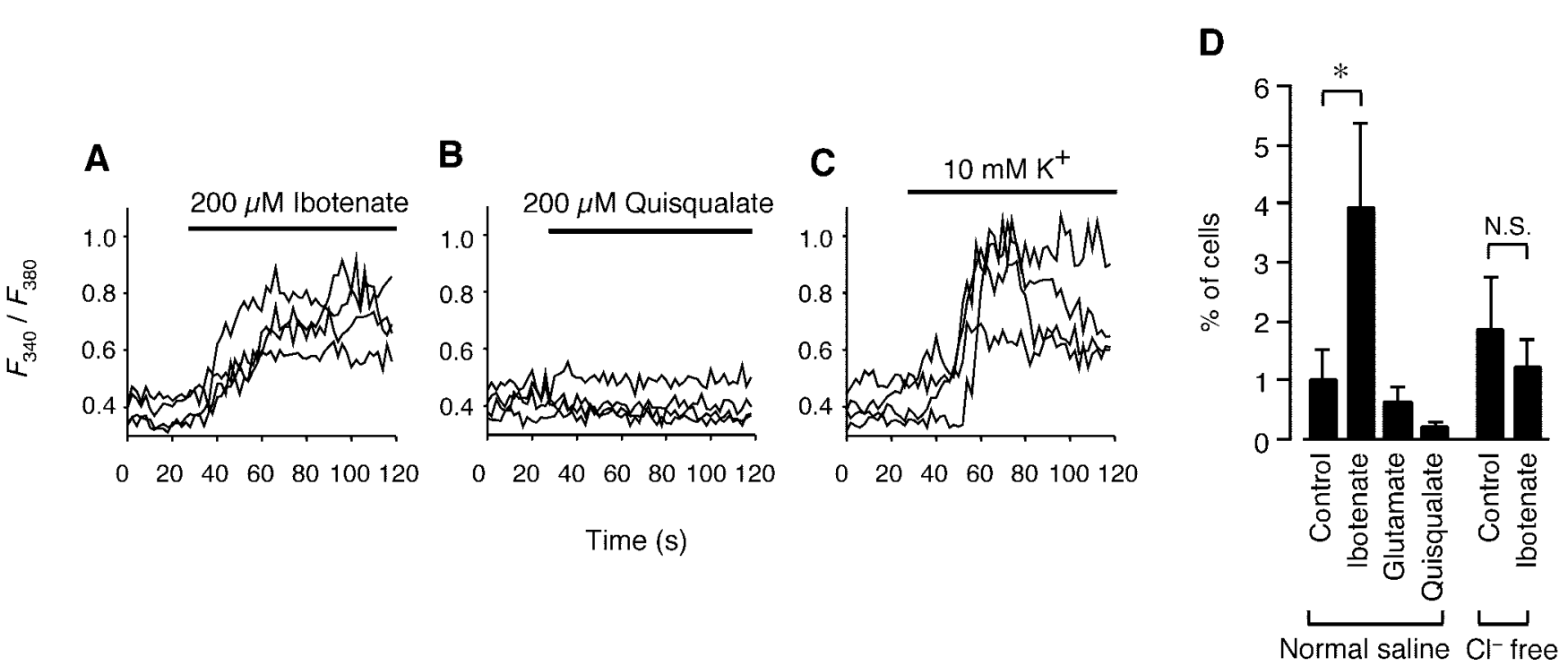

Figure 3. Changes in $\left[\mathrm{Ca}^{2+}\right]_{i}$ with ibotenate in cultured $\mathrm{PC}$ neurons revealed by calcium imaging. $A-C$, Example of four neurons that showed $\left[\mathrm{Ca}^{2+}\right]_{i}$ rises in response to ibotenate $(A)$. Traces of the ratio $\left(F_{340} / F_{380}\right)$ values are shown. Subsequently, the same neurons were stimulated with quisqualate $(B)$ and high $\mathrm{K}^{+}$saline (C).D, The percentage of the cells that showed an increase in the ratio values by $>0.2$ in response to various stimulus conditions. Note the small fraction of cells in the control group, which are spontaneously active cells often showing slow oscillations. Ibotenate caused $\left[\mathrm{Ca}^{2+}\right]_{\mathrm{i}}$ elevations in a significantly higher fraction of the neurons than the control in normal saline ( $t$ test; $\left.{ }^{*} p<0.05\right)$, whereas ibotenate had no significant (N.S.) effect on the cells under the $\mathrm{Cl}^{-}$-free condition.

1999). We used nystatin as the ionophore because nystatin produces a fairly low and stable access resistance. Whole-cell recording was not used in the present study because of the low success rate. The channel formed by nystatin permeates $\mathrm{Cl}^{-}$(Horn and Marty, 1988), and this allowed us to manipulate the cytoplasmic $\mathrm{Cl}^{-}$concentration $\left(\left[\mathrm{Cl}^{-}\right]_{\mathrm{i}}\right)$. With the $\mathrm{Cl}^{-}$-impermeable ionophore gramicidin (Ebihara et al., 1995), we could not obtain an access resistance low enough for analysis. First, the cerebral ganglion was isolated and the sheath covering the PC was removed mechanically. The preparation was placed on a microscope (BX50WI; Olympus) equipped with a $40 \times$ water immersion objective, and the electrode was visually guided onto a bursting neuron. Bursting neurons were identified on the basis of their soma size, which is larger than that of nonbursting neurons (Watanabe et al., 1998). To characterize the contribution of $\mathrm{Cl}^{-}$conductance in the spontaneous activity of bursting neurons, electrode solutions with two different compositions were used. The high $\mathrm{Cl}^{-}$solution $\left(80 \mathrm{~mm} \mathrm{Cl}^{-}\right)$contained the following: $70 \mathrm{mM} \mathrm{KCl}$, $5 \mathrm{~mm} \mathrm{MgCl} 2,5 \mathrm{~mm}$ HEPES, $\mathrm{pH} 7.6$, and $250 \mu \mathrm{g} / \mathrm{ml}$ nystatin. The low $\mathrm{Cl}^{-}$ solution $\left(10 \mathrm{mM} \mathrm{Cl}^{-}\right)$contained the following: $70 \mathrm{~mm} \mathrm{~K}$-gluconate, $5 \mathrm{~mm}$ $\mathrm{MgCl}_{2}, 5 \mathrm{~mm}$ HEPES, pH 7.6, and $250 \mu \mathrm{g} / \mathrm{ml}$ nystatin. The electrode resistance was $10-12 \mathrm{M} \Omega$, and the access resistance was $<200 \mathrm{M} \Omega$. As long as these recording conditions are followed, the cytoplasmic $\mathrm{Cl}^{-}$ concentration has been shown to become quickly equilibrated with the electrode solution (Watanabe et al., 1999). The recording was made in the current-clamp mode using a patch-clamp amplifier (EPC-7; List Electronic, Darmstadt-Eberstadt, Germany), and a negative DC current $(<40 \mathrm{pA}$ in amplitude) was injected to the electrode to keep the membrane hyperpolarized to a fixed value $(-90 \mathrm{mV})$. The amplitudes of five cycles of depolarizations were measured in each recording, and their average was plotted against the position of the cell body along the baseapex axis. The liquid junction potential $\left(6 \mathrm{mV}\right.$ for the high $\mathrm{Cl}^{-}$solution and $19 \mathrm{mV}$ for the low $\mathrm{Cl}^{-}$solution) was subtracted.

\section{Results}

\section{Effect of GluClR activation on the local field potential of} the PC

In normal saline, a regular LFP oscillation of $\sim 0.7 \mathrm{~Hz}$ was recorded from the surface of the PC. The oscillation in the LFP is thought to arise mainly from IPSPs in nonbursting neurons, which are presumably caused by periodic bursting in bursting neurons. Perfusion with glutamate ( $50 \mu \mathrm{M}$ to $1 \mathrm{~mm}$ ) suppressed the LFP oscillation. This is consistent with a previous report (Gelperin et al., 1993) and has been explained as a tonic hyperpolarization of the PC neurons attributable to the effect of glutamate on quisqualate-sensitive receptors (Watanabe et al., 1999). In two of nine preparations, however, glutamate slightly enhanced the oscillatory frequency before the oscillation was suppressed (Fig. 1A). This could be attributable to activation of a different subtype of glutamate receptor, presumably the GluClR. In fact, perfusion with 50-250 $\mu \mathrm{M}$ ibotenate augmented the frequency of the LFP oscillation in all of the six preparations tested (Figs. $1 B, 2 B$ ), possibly because of its selective effect on excitatory receptors. The LFP oscillation recovered to its initial level after the washout of ibotenate. These results suggest that the effect of glutamate on LFP oscillation is both excitatory and inhibitory, and the excitatory effect is mediated by the GluClR.

Because the ibotenate-induced current in the bursting neurons is carried by $\mathrm{Cl}^{-}$ions, the effects of ibotenate on the LFP oscillation were confirmed in a preparation incubated with $\mathrm{Cl}^{-}$free saline. Because $\left[\mathrm{Cl}^{-}\right]_{\mathrm{i}}$ in neurons easily becomes equilibrated with the external solution (Alvarez-Leefmans et al., 1988), the $\left[\mathrm{Cl}^{-}\right]_{\mathrm{i}}$ of the neurons under this condition is supposed to be virtually zero and the $\mathrm{Cl}^{-}$conductance to be no longer functional. In control preparations in normal saline, ibotenate caused a $20-580 \%$ increase in the oscillation frequency compared with the resting frequency $(n=6)$. In the preparation that had been incubated with $\mathrm{Cl}^{-}$-free saline, the resting LFP oscillation tended to be slower and often irregular, and only those preparations showing regular oscillations were used for analysis. In these preparations, ibotenate did not cause $>15 \%$ changes in the oscillatory frequency $(n=5)$ (Fig. 2). In three other preparations that showed irregular oscillations, no changes were observed in their excitability. Therefore, the effects of ibotenate are mediated by $\mathrm{Cl}^{-}$and unlikely to be mediated by unidentified receptors permeable to other ions. 


\section{Effect of GluClR activation in isolated PC neurons}

Because the network activity is a product of various types of neural interaction, we next asked whether individual PC neurons show excitation to ibotenate. We used a dissociated culture of PC neurons to observe the direct effect of ibotenate on isolated PC neurons. Perfusion with ibotenate evoked an increase in $\left[\mathrm{Ca}^{2+}\right]_{\mathrm{i}}$ in $4.0 \pm 1.4 \%$ of the cells (mean \pm SEM; summary of seven populations of cells; a total of 2968 cells were measured) (Fig. 3). Although a small fraction of the cells also showed a rise in $\left[\mathrm{Ca}^{2+}\right]_{\mathrm{i}}$ in control experiments $(1.0 \pm 0.5 \% ; n=4)$ attributable to spontaneous activity, the fraction of cells showing a rise in $\left[\mathrm{Ca}^{2+}\right]_{i}$ was significantly higher than in the control ( $t$ test; $p<0.05$ ). Perfusion with quisqualate or glutamate evoked a rise in $\left[\mathrm{Ca}^{2+}\right]_{\mathrm{i}}$ in a much smaller fraction of the cells $(0.6 \pm 0.3 \%, n=3$; or $0.2 \pm$ $0.1 \%, n=3$, respectively). Perfusion with high $\mathrm{K}^{+}$saline solution (containing $10 \mathrm{mM} \mathrm{K}{ }^{+}$) evoked a rise in $\left[\mathrm{Ca}^{2+}\right]_{\mathrm{i}}$ in $80.7 \pm 5.4 \%$ of the cells $(n=6)$. These results indicate that ibotenate causes a rise in $\left[\mathrm{Ca}^{2+}\right]_{\mathrm{i}}$ in a small fraction of PC cells, whereas glutamate and quisqualate have no excitatory effects.

To confirm that the $\left[\mathrm{Ca}^{2+}\right]_{\mathrm{i}}$ elevation induced by ibotenate is mediated by $\mathrm{Cl}^{-}$, intracellular $\mathrm{Cl}^{-}$was depleted by incubating the cells in $\mathrm{Cl}^{-}$-free saline. In the $\mathrm{Cl}^{-}$-free control, $1.9 \pm 0.9 \%$ of the cells $(n=6)$ showed spontaneous rises in $\left[\mathrm{Ca}^{2+}\right]_{\mathrm{i}}$, whereas $1.2 \pm 0.5 \%$ of the cells $(n=6)$ showed a rise in $\left[\mathrm{Ca}^{2+}\right]_{\mathrm{i}}$ with ibotenate, which was not significantly different from the control. Perfusion with high $\mathrm{K}^{+}$saline still evoked a $\left[\mathrm{Ca}^{2+}\right]_{\mathrm{i}}$ elevation in $68.9 \pm 5.5 \%$ of the cells $(n=4)$ in $\mathrm{Cl}^{-}$-free saline. These results indicate that the $\left[\mathrm{Ca}^{2+}\right]_{\mathrm{i}}$ elevation with ibotenate requires functioning $\mathrm{Cl}^{-}$conductance.

\section{Effect of GluClR activation in the whole PC}

Calcium imaging in the intact PC revealed periodic $\left[\mathrm{Ca}^{2+}\right]_{\mathrm{i}}$ waves propagating in the apex-to-base direction (Fig. 4). These $\left[\mathrm{Ca}^{2+}\right]_{\mathrm{i}}$ waves have been shown to be synchronous with the membrane potential oscillation (Inoue et al., 1998), and the $\left[\mathrm{Ca}^{2+}\right]_{\mathrm{i}}$ signal is thought to arise mainly from bursting neurons because they always burst periodically. Calcium imaging with a single neuron resolution has revealed periodic $\left[\mathrm{Ca}^{2+}\right]_{\mathrm{i}}$ oscillations in bursting neurons (Wang et al., 2001). Perfusion with ibotenate elevated the $\left[\mathrm{Ca}^{2+}\right]_{\mathrm{i}}$ level as well as the frequency of $\left[\mathrm{Ca}^{2+}\right]_{\mathrm{i}}$ oscillation (Fig. 5). The ibotenate-induced $\left[\mathrm{Ca}^{2+}\right]_{\mathrm{i}}$ elevation was higher in the apical region of the $\mathrm{PC}$ than in the basal region when normalized by the amplitudes of the periodic events before stimulation $(29.6 \pm 8.5 \%$ for the regions in the apical half and $11.6 \pm 6.1 \%$ for the regions in the basal half; paired $t$ test; $p<$ $0.05 ; n=10$, only preparations with stable baseline fluorescence were included; total number of experiments, 13). The frequency measured at the apical region rose by $135 \pm 55 \%(n=13)$. At the peak of the ibotenate-induced $\left[\mathrm{Ca}^{2+}\right]_{\mathrm{i}}$ elevation, the oscillation frequency was often greater in the apical region than in the basal region, indicating that some of the $\left[\mathrm{Ca}^{2+}\right]_{\mathrm{i}}$ waves initiated at the apical site failed to propagate to the basal region. Such locally restricted events were observed in 7 of 13 preparations. Local events were also observed in one of four other preparations in which recording was made only for part of the period of ibotenate perfusion. This could be attributable to a limited capability of the neural connections to transmit excitation. The events that failed to propagate to the basal site did not seem like the double events described previously (Kleinfeld et al., 1994), because the intervals between the events were still fairly uniform rather than being an alternation of long and short intervals.

In $\mathrm{Cl}^{-}$-free saline, spontaneous $\left[\mathrm{Ca}^{2+}\right]_{\mathrm{i}}$ oscillation still occurred in the PC. However, the direction of wave propagation
A
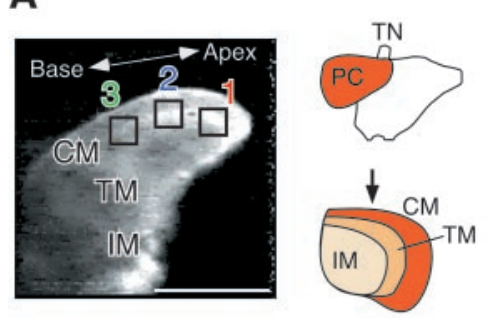

C
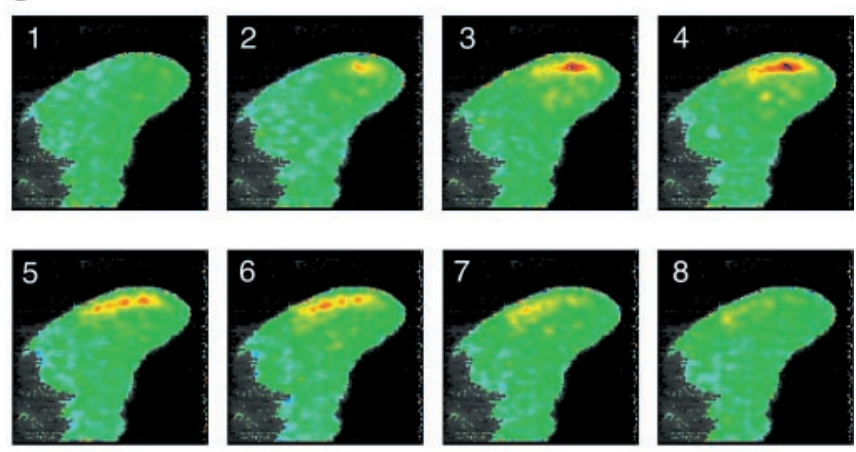

$\triangle F I F$

$0+5 \%$

Figure 4. Calcium oscillation in the $P C$. $A$, Fluorescence image of the $P C$ stained with rhod-2 AM, observed from the dorsal side. CM, Cell mass; TM, terminal mass; IM, internal mass. Scale bar, $400 \mu \mathrm{m}$. The schemes on the right indicate the location of the PC in the cerebral ganglion (top) and the direction of the observation of the $P C$ (arrow in the bottom), which visualizes the three layers of the $P C$. $T N$, Tentacle nerve. $B$, Time courses of the relative fluorescence $(\Delta F / F)$ at the three outlined regions shown in the image in $A$, indicating the time lag in the $\left[\mathrm{Ca}^{2+}\right]_{i}$ signals between the regions. C, A series of images taken every $76.8 \mathrm{msec}$. The pseudocolor indicates the relative fluorescence. Note that the strong $\left[\mathrm{Ca}^{2+}\right]_{i}$ rise is restricted to the cell mass, the layer that contains the cell bodies of the $P C$ neurons, and the neurites of the bursting neurons project therein.

was reversed and became base-to-apex $(n=3)$, and the frequency tended to be lower than in normal saline (Fig. $6 B$ ). Perfusion with ibotenate $(200 \mu \mathrm{M})$ in $\mathrm{Cl}^{-}$-free saline had little or no effect on the $\left[\mathrm{Ca}^{2+}\right]_{\mathrm{i}}$ oscillation in any of the three preparations (Fig. $6 \mathrm{C}$ ). The direction of wave propagation was still in the base-to-apex direction. These results also indicate that $\mathrm{Cl}^{-}$is required for the $\left[\mathrm{Ca}^{2+}\right]_{\mathrm{i}}$ elevation caused by ibotenate in the intact PC. In $\mathrm{Na}^{+}$free saline, no spontaneous activity was observed, indicating that spontaneous oscillatory activity requires extracellular $\mathrm{Na}^{+}$(data not shown). Perfusion with ibotenate caused no $\left[\mathrm{Ca}^{2+}\right]$ increase in the $\mathrm{Na}^{+}$-free condition.

\section{$\mathrm{Cl}^{-}$-dependent potentials in the bursting neuron}

To clarify the contribution of $\mathrm{Cl}^{-}$conductance to the propagation of waves, the activities of single bursting neurons in the PC were recorded by patch-clamp recording using electrodes containing a high $(80 \mathrm{~mm})$ or low $(10 \mathrm{~mm})$ concentration of $\mathrm{Cl}^{-}$. When recorded with the high $\mathrm{Cl}^{-}$electrode and a hyperpolarizing DC current to keep the membrane potential hyperpolarized to $-90 \mathrm{mV}$, subthreshold depolarizing potentials were recorded. The amplitudes of these potentials were highly variable between different neurons, and some bursting neurons showed very large amplitudes $(21.8 \pm 2.7 \mathrm{mV} ; n=16)$ (Fig. 7A). In these neurons, the potentials tended to become larger at a more hyperpolarized potential with a larger current injection, suggesting that these potentials are mainly synaptic potentials. In the bursting neurons showing relatively small potentials, on the other hand, the ampli- 

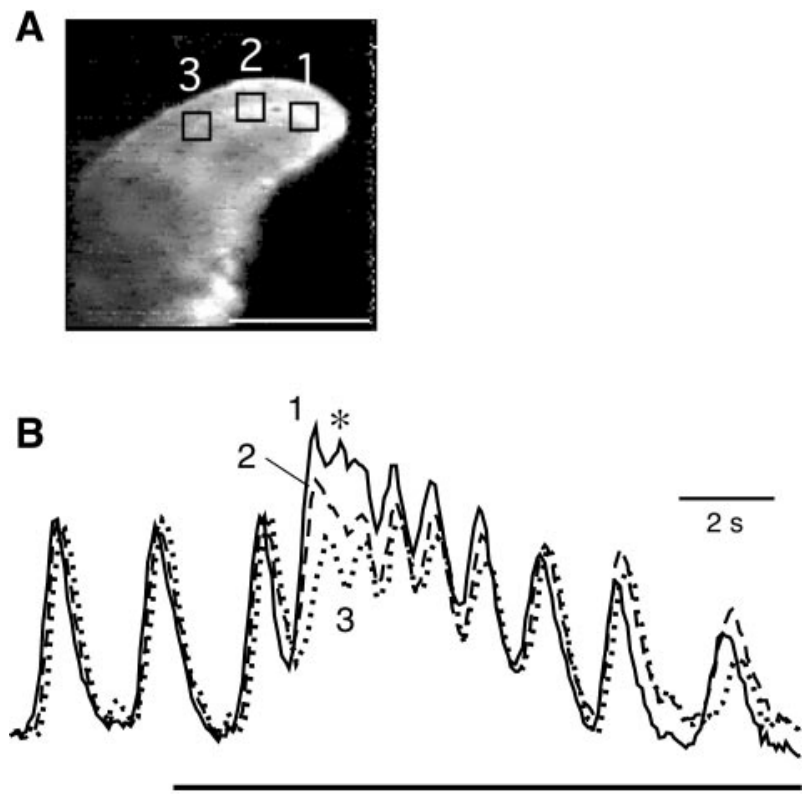

$200 \mu \mathrm{M}$ lbotenate

Figure 5. Calcium elevation with ibotenate in the intact $P C$. $A$, Fluorescence image of the $P C$ used for the recording. Scale bar, $400 \mu \mathrm{m} . B$, Time courses of normalized fluorescence for the three outlined regions shown in $A$. The traces have been normalized to give the same resting amplitudes of the $\left[\mathrm{Ca}^{2+}\right]_{\mathrm{i}}$ events. The apical region (region 1) shows the highest $\left[\mathrm{Ca}^{2+}\right]_{\mathrm{i}}$ rise, and one event in region 1 , indicated by the asterisk, failed to propagate to the basal regions (regions 2 and 3).

A

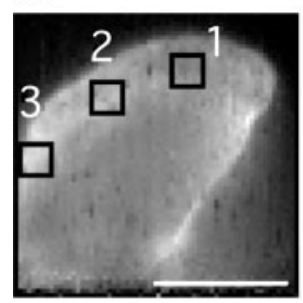

B
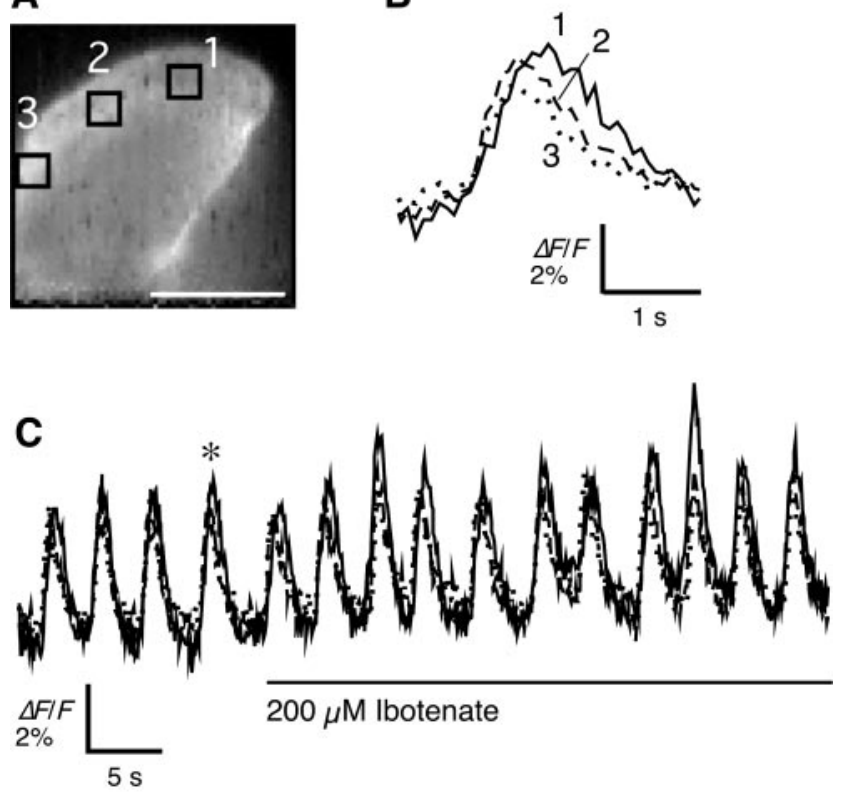

Figure 6. Effect of ibotenate on $\left[\mathrm{Ca}^{2+}\right]_{\mathrm{i}}$ in $\mathrm{Cl}^{-}$-free saline. $A$, Fluorescence image of the $\mathrm{PC}$, showing the regions selected for the traces in $B$ and C. Scale bar, $200 \mu \mathrm{m}$. B, Time course of a $\left[\mathrm{Ca}^{2+}\right]_{\mathrm{i}}$ event (relative fluorescence) in $\mathrm{Cl}^{-}$-free saline. These traces are from the three outlined regions shown in $A$ and also an expansion of the event with the asteriskin $C$. The $\left[\mathrm{Ca}^{2+}\right]_{\mathrm{j}}$ riseoccurs earlier in the basal region than in the apical region. C, Time course of the relative fluorescence in the selected regions in a slower scan, indicating that ibotenate has no effect in the absence of $\mathrm{Cl}^{-}$.

tudes did not depend much on the membrane potential. With the low $\mathrm{Cl}^{-}$electrode (Fig. $7 B$ ), the amplitudes of the spontaneous potentials were generally small $(12.3 \pm 1.3 \mathrm{mV} ; n=16)$, and the amplitudes showed little voltage dependence. These results sug-
High $\mathrm{Cl}^{-}$electrode

Low $\mathrm{Cl}^{-}$electrode

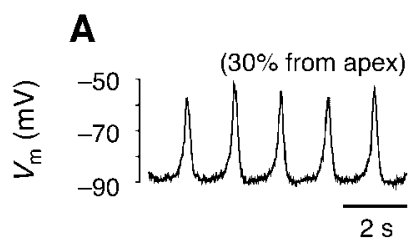

B

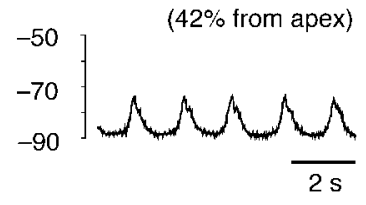

\section{C}

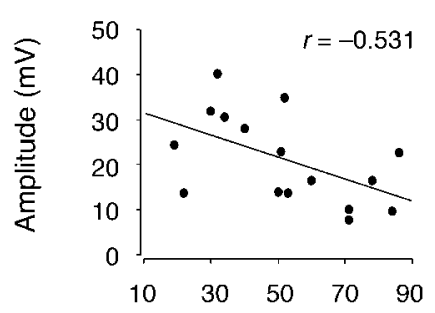

D

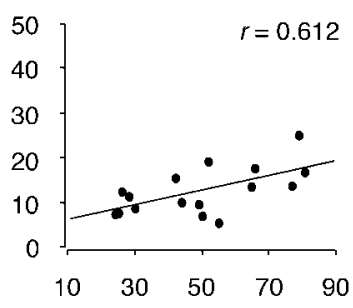

Location (\% from apex)

Figure 7. Spontaneous activities of bursting neurons recorded with the current-clamp mode of perforated patch recording. $A$ negative $D C$ current was injected to adjust the bottom level of the potential to $-90 \mathrm{mV}$. A, An example of a bursting neuron recorded with a high $\mathrm{Cl}^{-}$ electrode. This neuron was positioned at $30 \%$ from the apex of the $\mathrm{PC}$. $B$, An example of a bursting neuron recorded with a low $\mathrm{Cl}^{-}$electrode. This neuron was located at $42 \%$ from the apex of the PC. C, A plot of the amplitude of the periodic depolarizations against the location in the $\mathrm{PC}$ recorded with a high $\mathrm{Cl}^{-}$electrode. Neurons in the apical area showed larger amplitudes, and the correlation was significant $(p<0.05)$. Each point is the average of the amplitudes of five events in a neuron. The waveforms of the depolarizations were highly regular, and the SEMs for each data point never exceeded $1 \mathrm{mV}$ (data not indicated). D, A plot of the amplitude of the periodic depolarizations against the location in the $\mathrm{PC}$ recorded with a low $\mathrm{Cl}^{-}$ electrode. Neurons in the apical area showed smaller amplitudes, and the correlation was significant $(p<0.05)$.

gest that, in bursting neurons, $\mathrm{Cl}^{-}$channels are activated periodically to cause periodic depolarizations, although $\mathrm{Cl}^{-}$-independent components also exist.

Interestingly, bursting neurons in the apical area showed larger periodic depolarizations than did those in the basal region when recorded with the high $\mathrm{Cl}^{-}$electrode (Fig. 7C). The correlation between the amplitude and the location of the cell was statistically significant (Pearson's correlation coefficient; $r=$ $-0.531 ; p<0.05)$. In contrast, the apical bursting neurons showed slightly smaller depolarizations than the basal bursting neurons when the neurons were recorded with the low $\mathrm{Cl}^{-}$electrode $(r=0.612 ; p<0.05)$ (Fig. $7 D)$. In the neurons located in the apical half of the PC, the amplitudes of the depolarizations recorded with the high $\mathrm{Cl}^{-}$and low $\mathrm{Cl}^{-}$electrodes were significantly different $\left(26.2 \pm 3.6 \mathrm{mV}\right.$ for high $\mathrm{Cl}^{-}$and $9.9 \pm 0.9 \mathrm{mV}$ for low $\mathrm{Cl}^{-}$; $t$ test; $\left.p<0.01\right)$. In contrast, there was no significant difference in the amplitudes in the bursting neurons in the basal half of the PC between the high $\mathrm{Cl}^{-}$and low $\mathrm{Cl}^{-}$conditions

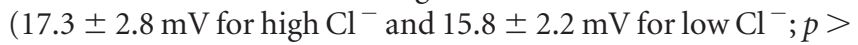
0.1 ). These are consistent with the results above, indicating that the direction of wave propagation depends on $\mathrm{Cl}^{-}$-dependent excitability and is possibly related to the spatial difference in excitability or the intrinsic oscillation frequency of the local circuits.

\section{Discussion}

In the present work, we presented evidence that GluClR acts as an excitatory channel in the Limax PC neurons and that it is involved in the periodic wave propagation in the apex-to-base direction. To summarize the results, (1) ibotenate evoked a $\left[\mathrm{Ca}^{2+}\right]_{\mathrm{i}}$ 

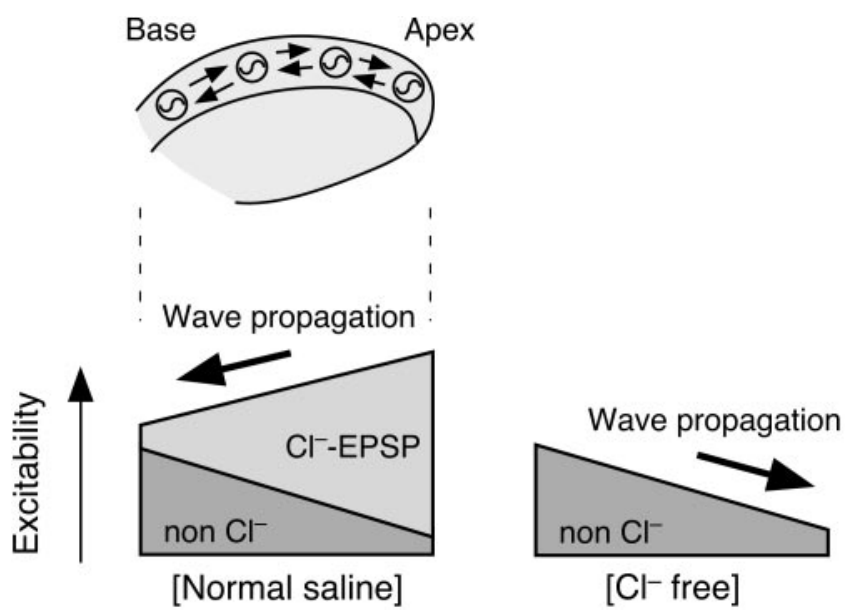

Figure 8. Scheme of the suggested mechanism for the propagation of waves in the PC. Left, Under normal conditions, the apical region has a higher intrinsic oscillatory frequency attributable to a higher excitability caused by $\mathrm{Cl}^{-}$-mediated synaptic transmission. This results in waves propagating in the apex-to-base direction. Right, Under the $\mathrm{Cl}^{-}$-free condition, in which $\mathrm{Cl}^{-}$-dependent synaptic transmission is blocked, the basal region has a higher excitability, and this results in waves propagating in the base-to-apex direction.

elevation in both isolated PC neurons (Fig. 3) and in the intact PC (Fig. 5), and this elevation was dependent on extracellular $\mathrm{Cl}^{-}$; (2) ibotenate evoked a stronger excitation in the apical region of the PC (Fig. 5); (3) normally, the wave propagates from the apex to the base, whereas in the absence of functional $\mathrm{Cl}^{-}$conductances, the wave propagates from the base to the apex (Fig. 6); and (4) apical bursting neurons showed larger EPSP-like potentials whose amplitude depended on the $\mathrm{Cl}^{-}$concentration of the electrode, whereas no $\mathrm{Cl}^{-}$-dependent potentials were observed in the basal bursting neurons (Fig. 7). All of these results suggest that the excitatory $\mathrm{Cl}^{-}$conductance localized in the apical region is responsible for the higher excitability (and hence the higher intrinsic oscillation frequency) of the apical network.

The difference in the intrinsic local frequency explains the direction of wave propagation in a well documented manner (Ermentrout et al., 1998). A detailed oscillator model of the PC is also consistent with the propagation of waves in experiments under various conditions, including the low $\mathrm{Cl}^{-}$condition, which evokes a reversal in the direction of wave propagation (Ermentrout et al., 1998). Consistent with the theory, the small pieces of local circuits cut out from the PC have different intrinsic oscillatory frequencies, with the highest frequency at the apical site and the lowest frequency at the base (Ermentrout et al., 1998). Stronger excitatory connections within the local circuit will result in a higher frequency of the network.

The reversed wave propagation under the $\mathrm{Cl}^{-}$-free condition may be attributable to a spatial gradient in the density of synaptic interactions mediated by mechanisms other than GluClRs, more of which might be functioning in the basal network. The $\mathrm{Cl}^{-}$independent component of the periodic depolarizations could be mediated by electrical synapses (Wang et al., 2000), as well as other chemical synaptic mechanisms, including cholinergic transmissions (Watanabe et al., 2001). The scheme explained above is summarized in Figure 8.

In the mammalian neocortex, nonselective cation conductance mediated by AMPA receptors makes a major contribution to the generation of traveling waves, because they are strongly suppressed by the AMPA receptor antagonist CNQX (Golomb and Amitai, 1997). It should be noted that a network with mutual inhibitory connections could also produce traveling waves by means of a rebound depolarization, as has been demonstrated in a modeling study (Rinzel et al., 1998). However, the propagation speed is much lower than in a network with mutual excitatory connections, because neurons fire and transmit signals only after a full recovery from the inhibitory input. Apparently, this mode of wave propagation is not likely to occur in the PC neurons, because there is no evidence for prominent hyperpolarizations or rebound potentials in the bursting PC neurons. The possibility that $\mathrm{Cl}^{-}$conductance exerts its effect on wave propagation through an inhibitory action is, therefore, unlikely. In addition, recent work has shown that lowered $\left[\mathrm{Cl}^{-}\right]_{\mathrm{i}}$ may lead to a tonic influx of cations and to bursting activity (Beck et al., 2001). This might explain the relatively extended duration of the $\left[\mathrm{Ca}^{2+}\right]_{i}$ events under the $\mathrm{Cl}^{-}$-free condition.

Because only bursting neurons have GluClRs in the PC (Watanabe et al., 1999), the neurons that showed $\left[\mathrm{Ca}^{2+}\right]_{\mathrm{i}}$ elevations and triggered the increase in the oscillation frequency in response to ibotenate should be bursting neurons. In a random sample, $\sim 10 \%$ of the total PC neurons were reported to be bursting neurons (Kleinfeld et al., 1994). In the present report, we showed that approximately one-half of the recorded bursting neurons showed a large-amplitude oscillation using a high $\mathrm{Cl}^{-}$electrode, which was thought to be mediated by $\mathrm{Cl}^{-}$(Fig. 7C). These data are consistent with the result in isolated $\mathrm{PC}$ neurons that $\sim 4 \%$ of the total PC neurons showed excitation after the application of ibotenate (Fig. 3). Thus far, bursting and nonbursting neurons have been identified in the PC, and only the former respond to ibotenate (Watanabe et al., 1999); therefore, the results strongly suggest that the affected neurons in the culture were bursting neurons. Recently, Wang et al. (2001) demonstrated the existence of two morphologically distinct subtypes of bursting neurons. Future studies are needed to relate the physiological and morphological characteristics of bursting neuron subtypes.

The GluClR in the Limax bursting PC neurons has similar pharmacological and kinetic characteristics with those receptors found in many invertebrate neurons and muscles (Cleland, 1996). However, their roles have been mostly unknown. The ibotenate-induced excitation was thought to occur as a result of a relatively high equilibrium potential for $\mathrm{Cl}^{-}$in the bursting neurons, as has been demonstrated for the mammalian excitatory $\mathrm{GABA}_{\mathrm{A}}$ responses (Luhman and Prince, 1991; Leinekugel et al., 1995; Serafini et al., 1995; Chen et al., 1996; Owens et al., 1996; Wagner et al., 1997). In mammalian neurons, $\left[\mathrm{Cl}^{-}\right]_{\mathrm{i}}$ is regulated by $\mathrm{K}^{+} / \mathrm{Cl}^{-}$and $\mathrm{Na}^{+} / \mathrm{K}^{+} / 2 \mathrm{Cl}^{-}$cotransporters (Misgeld et al., 1986), and a developmental change in the $\mathrm{Na}^{+} / \mathrm{K}^{+} / 2 \mathrm{Cl}^{-} \mathrm{CO}^{-}$ transporters may explain the excitatory actions of GABA in specific stages during development (Marty et al., 2002). Cytoplasmic $\mathrm{Cl}^{-}$concentrations are highly variable between neurons. For example, $\left[\mathrm{Cl}^{-}\right]_{\mathrm{i}}$ in two identified Helix neurons were 11.2 and 24.7 mm (Kerkut and Meech, 1966). The latter value would give a reversal potential of $-42 \mathrm{mV}$ in Helix saline, and similar values are therefore possible in the Limax neurons. Although excitatory $\mathrm{Cl}^{-}$conductances have been regarded as exceptional phenomena, our findings that excitatory $\mathrm{Cl}^{-}$conductance regulates a large-scale network activity suggest a novel role for $\mathrm{Cl}^{-}$conductance in the CNS.

\section{References}

Alvarez-Leefmans FJ, Gamino SM, Giraldez F, Nogueron I (1988) Intracellular chloride regulation in amphibian dorsal root ganglion neurones studied with ion-selective microelectrodes. J Physiol (Lond) 406:225-246. Beck A, Lohr C, Nett W, Deitmer JW (2001) Bursting activity in leech 
Retzius neurons induced by low external chloride. Pflügers Arch 442:263-272.

Chen G, Trombley PQ, van den Pol AN (1996) Excitatory actions of GABA in developing rat hypothalamic neurones. J Physiol (Lond) 494:451-464.

Cleland TA (1996) Inhibitory glutamate receptor channels. Mol Neurobiol 13:97-136.

Ebihara S, Shirato K, Harata N, Akaike N (1995) Gramicidin-perforated patch recording: GABA response in mammalian neurones with intact intracellular chloride. J Physiol (Lond) 484:77-86.

Ermentrout B, Flores J, Gelperin A (1998) Minimal model of oscillations and waves in the Limax olfactory lobe with tests of the model's predictive power. J Neurophysiol 79:2677-2689.

Ermentrout GB, Kleinfeld D (2001) Traveling electrical waves in cortex: insights from phase dynamics and speculation on a computational role. Neuron 29:33-44.

Gelperin A (1999) Oscillatory dynamics and information processing in olfactory systems. J Exp Biol 202:1855-1864.

Gelperin A, Tank DW (1990) Odour-modulated collective network oscillations of olfactory interneurons in a terrestrial mollusc. Nature 345:437-440.

Gelperin A, Rhines LD, Flores J, Tank DW (1993) Coherent network oscillations by olfactory interneurons: modulation by endogenous amines. J Neurophysiol 69:1930-1939.

Gervais R, Kleinfeld D, Delaney KR, Gelperin A (1996) Central and reflex neuronal responses elicited by odor in a terrestrial mollusk. J Neurophysiol 76:1327-1339.

Golomb D, Amitai Y (1997) Propagating neuronal discharges in neocortical slices: computational and experimental study. J Neurophysiol 78:1199-1211.

Horn R, Marty A (1988) Muscarinic activation of ionic currents measured by a new whole-cell recording method. J Gen Physiol 92:145-159.

Inoue T, Kawahara S, Toda S, Watanabe S, Kirino Y (1998) Selective optical recording of the neural activity in the olfactory center of land slug using a calcium indicator dye. Bioimages 6:59-67.

Kawahara S, Toda S, Suzuki Y, Watanabe S, Kirino Y (1997) Comparative study on neural oscillation in the procerebrum of the terrestrial slugs Incilaria bilineata and Limax marginatus. J Exp Biol 200:1851-1861.

Kerkut GA, Meech RW (1966) The internal chloride concentration of $\mathrm{H}$ and D cells in the snail brain. Comp Biochem Physiol 19:819-832.

Kleinfeld D, Delaney KR, Fee MS, Flores JA, Tank DW, Gelperin A (1994) Dynamics of propagating waves in the olfactory network of a terrestrial mollusc: an electrical and optical study. J Neurophysiol 72:1402-1419.

Lam YW, Cohen LB, Wachowiak M, Zochowski MR (2000) Odors elicit three different oscillations in the turtle olfactory bulb. J Neurosci $20: 749-762$.

Leinekugel X, Tseeb V, Ben-Ari Y, Bregestovski P (1995) Synaptic GABA activation induces $\mathrm{Ca}^{2+}$ rise in pyramidal cells and interneurons from rat neonatal hippocampal slices. J Physiol (Lond) 487:319-329.

Luhman HJ, Prince DA (1991) Postnatal maturation of the GABAergic system in rat neocortex. J Neurophysiol 65:247-263.
Marty S, Wehrlé R, Alvarez-Leefmans FJ, Gasnier B, Sotelo C (2002) Postnatal maturation of $\mathrm{Na}^{+}, \mathrm{K}^{+}, 2 \mathrm{Cl}^{-}$cotransporter expression and inhibitory synaptogenesis in the rat hippocampus: an immunocytochemical analysis. Eur J Neurosci 15:233-245.

Misgeld U, Deisz RA, Dodt HU, Lux HD (1986) The role of chloride transport in postsynaptic inhibition of hippocampal neurons. Science 232:1413-1415

Owens DF, Boyce LH, Davis MBE, Kriegstein AR (1996) Excitatory GABA responses in embryonic and neonatal cortical slices demonstrated by gramicidin perforated-patch recordings and calcium imaging. J Neurosci 16:6414-6423.

Prechtl JC, Cohen LB, Pesaran B, Mitra PP, Kleinfeld D (1997) Visual stimuli induce waves of electrical activity in turtle cortex. Proc Natl Acad Sci USA 94:7621-7626.

Rhines LD, Sokolove PG, Flores J, Tank DW, Gelperin A (1993) Cultured olfactory interneurons from Limax maximus: Optical and electrophysiological studies of transmitter-evoked responses. J Neurophysiol 69:1940-1947.

Rinzel J, Terman D, Wang X, Ermentrout B (1998) Propagating activity patterns in large-scale inhibitory neuronal networks. Science 279:1351-1355.

Ritz R, Sejnowski TJ (1997) Synchronous oscillatory activity in sensory systems: new vistas on mechanisms. Curr Opin Neurobiol 7:536-546.

Sanchez-Vives MV, McCormick DA (2000) Cellular and network mechanisms of rhythmic recurrent activity in neocortex. Nat Neurosci 3:1027-1034.

Serafini R, Valeyev AY, Barker JL, Poulter MO (1995) Depolarizing GABAactivated $\mathrm{Cl}^{-}$channels in embryonic rat spinal and olfactory bulb cells. J Physiol (Lond) 488:371-386.

Wagner S, Castel M, Gainer H, Yarom Y (1997) GABA in the mammalian suprachiasmatic nucleus and its role in diurnal rhythmicity. Nature 387:598-603.

Wang JW, Flores J, Gelperin A (2000) An olfactory oscillatory network connected by both chemical and electrical synapses. Soc Neurosci Abstr 26:759.10.

Wang JW, Denk W, Flores J, Gelperin A (2001) Initiation and propagation of calcium-dependent action potentials in a coupled network of olfactory interneurons. J Neurophysiol 85:977-985.

Watanabe S, Kawahara S, Kirino Y (1998) Morphological characterization of the bursting and nonbursting neurones in the olfactory centre of the terrestrial slug Limax marginatus. J Exp Biol 201:925-930.

Watanabe S, Kawahara S, Kirino Y (1999) Glutamate induces $\mathrm{Cl}^{-}$and $\mathrm{K}^{+}$ currents in the olfactory interneurons of a terrestrial slug. J Comp Physiol [A] 184:553-562.

Watanabe S, Inoue T, Murakami M, Inokuma Y, Kawahara S, Kirino Y (2001) Modulation of oscillatory neural activities by cholinergic activation of interneurons in the olfactory center of a terrestrial slug. Brain Res 896:30-35. 